\title{
筒|restice
}

\section{Avaliação da ficha de coqueluche dos casos positivos em dois municípios do interior paulista}

Evaluation of the coqueluche detail of positive cases in two municipalities of the paulista interior

\author{
Paula Fernandes Chadi ${ }^{1}$, Lívia Faria Orso ${ }^{2}$, Amanda de Lima e Silva ${ }^{3}$, Rafaela \\ Aparecida Prata de Oliveira ${ }^{4}$, Gabriela Corrêa Carvalho ${ }^{5}$, lone Corrêa ${ }^{6}$.
}

\begin{abstract}
Resumo
Introdução: A notificação compulsória consiste na comunicação de agravos ou doenças relacionadas na portaria $n^{\circ}$ 204, constitui políticas de informações em saúde possibilitando registro eletrônicos em saúde. Objetivo: Avaliar o preenchimento da ficha de notificação compulsória para a doença coqueluche entre zero a quatro anos confirmadas positivas no período de 2008 a 2016, nos municípios de Botucatu e Marília no estado de São Paulo. Métodos: Estudo epidemiológico, descritivo de delineamento transversal, que avaliou a qualidade do preenchimento dos itens contidos em 159 fichas de notificação compulsória para coqueluche dos casos positivos entre zero e quatro anos. Resultados: Do total de 159 fichas de notificação analisadas, 72 (45,29\%) casos foram notificados no município de Botucatu e 87 (54,71\%) no município de Marília. Todas as fichas analisadas foram categorizadas com parcialmente preenchida. Alguns itens considerados facultativos que podem ter comprometido qualitativamente o controle da doença. Conclusão: Os dados revelaram a necessidade de ações de educação em saúde sobre a importância do preenchimento do instrumento, bem como a revisão dos itens considerados facultativos.
\end{abstract}

Palavras-Chave: Coqueluche; Epidemiologia; Notificação compulsória; Prevenção e Controle.

\section{Abstract}

Introduction: Compulsory notification consists of the communication of diseases or related diseases in Ordinance No. 204, constitutes health information policies enabling electronic health records. Objective: To evaluate the completion of the compulsory notification form for pertussis between zero and four years of positive results from 2008 to 2016 in the municipalities of Botucatu and Marilia in the state of São Paulo. Methods: Epidemiological study, descriptive of a cross sectional design, that evaluated the quality of filling the items contained in 159 compulsory notification sheets for pertussis from positive cases between zero and four years. Results: Of the total of 159 notification forms analyzed, 72 (45,29\%) cases were reported in the city of Botucatu and 87 (54,71\%) in the municipality of Marilia. All the analyzed chips were categorized with partially filled. Some items considered optional that

\footnotetext{
1 Doutora. Universidade Estadual Paulista; Fundação Educacional do Município de Assis. E-mail: pchadi@hotmail.com.br 2 Mestre. Universidade Estadual Paulista. E-mail: livia orso@hotmail.com

3 Especialista. Universidade Estadual Paulista. E-mail: mandahlima@hotmail.com

4 Mestre. Universidade Estadual Paulista. E-mail: rafaela17prata@hotmail.com

5 Mestre. Faculdade de Ciências Farmacêuticas. Universidade de São Paulo. E-mail: gabrielacarvalho57@yahoo.com

6 Próf. Doutora. Universidade Estadual Paulista. E-mail: ione.correa@unesp.br

Correspondência: Fundação Educacional do Município de Assis "FEMA" - Assis/São Paulo. Endereço: Av. Getúlio Vargas, 1200 - Vila Nova Santana; CEP:19807-130. Telefone (18)3302-1055 (Ramal:1209 - Coordenação de Medicina).
} 
may have qualitatively compromised the control of the disease. Conclusion: The data revealed the need for health education actions on the importance of completing the instrument, as well as the review of items considered as optional.

Keywords: Whooping cough; Epidemiology; Mandatory reporting; Prevention and control.

Aprovado pelo Comitê de Ética em Pesquisa ํㅜㄹ.485.887 de 5 de fevereiro de 2018 .

\section{Introdução}

A notificação compulsória consiste na comunicação de agravos ou doenças relacionadas na portaria $\mathrm{n}^{\circ} \mathbf{2 0 4}$, constitui políticas de informações em saúde possibilitando registro eletrônicos em saúde ${ }^{1-4}$. De acordo com o artigo $8^{0}$ da Lei no 6.259 , de 30 de outubro de 1975, esta notificação é obrigatória para os médicos, outros profissionais de saúde e responsáveis pelos serviços públicos e privados de saúde ${ }^{5,6}$.

As fichas de notificação compulsória alimentam o Sistema de Informação de Agravos de Notificação (SINAN), que foi desenvolvido nos anos de 1990 e 19937, estes dados permitem calcular incidência, prevalência, letalidade e mortalidade, bem como realizar análises e avaliar a qualidade dos dados fornecidos.

Estudos realizados mostram que há falta de conhecimento dos profissionais e da população sobre as características clínicas das doenças, sobre o sistema de notificação no país e seu preenchimento, o qual não é valorizado ${ }^{8-10}$. Contudo, a informação é essencial para a tomada de decisões, pois, com o preenchimento de todos os campos da ficha pode-se obter um diagnóstico situacional mais próximo da realidade ${ }^{11,12}$.

Deste contexto, surgiram, então, as perguntas para esta pesquisa. Vale lembrar, entretanto, que este estudo teve como objetivo avaliar a qualidade dos dados preenchidos nas fichas de notificação compulsória para a doença coqueluche em crianças entre zero e quatro anos confirmadas positivas no período de 2008 a 2016 nos municípios de Botucatu e Marília no estado de São Paulo.

\section{Métodos}

Trata-se de um estudo quantiqualitativo, descritivo de delineamento transversal, que avaliou o preenchimento dos itens contidos na ficha de notificação compulsória (FNC) para coqueluche em crianças entre zero e quatro anos no período de 2008 a 2014 nos municípios de Marília e Botucatu no estado de São Paulo.

Ressalta-se que as FNC estão disponíveis para os profissionais de saúde em forma de tecnologia lecto-escrita e, posteriormente, são encaminhadas para a vigilância epidemiológica do município. Os dados são transcritos no formato digital, que pertence ao banco de dados do Sistema de Informação de Agravos de 
Notificação (SINAN), de acesso restrito aos serviços de saúde.

Os municípios de estudo foram escolhidos por conveniência e por tratar-se de municípios com hospitais de referência para regional de saúde, sendo elas DRS VI de Botucatu e DRS IX de Marília; sendo assim, as fichas analisadas correspondem à regional de saúde a que pertencem.

Este estudo foi realizado didaticamente em duas etapas. A primeira etapa consistiu da análise das fichas de notificação compulsória para doença coqueluche, no formato lecto-escrito e digital, as fichas foram analisadas do período de janeiro de 2008 a dezembro de 2016, na Vigilância Epidemiológica dos municípios de Botucatu e Marília.

A segunda etapa destinou-se à tabulação dos dados dos respectivos municípios separadamente. Seguida da análise comparativa de ambos os municípios.

Para elegibilidade das fichas de notificação, deveria ter acesso na íntegra ao formato lecto-escrito e digital. Os campos a serem preenchidos eram considerados preenchidos quando estavam completos e legíveis. Foram considerados não preenchidos quando estavam incompletos ou não preenchidos.

Este método foi utilizado seguindo as instruções do preenchimento das fichas de coqueluche pelo SINAN e conforme orientações do Caderno no 3 da Secretaria de Saúde do Estado de São Paulo ${ }^{13,14}$.
O instrumento de coleta de dados foi a reprodução da própria ficha em uma planilha Excel, com duas colunas, a primeira foi assinalada se o campo estivesse preenchido completo e legível, identificando como item preenchido. A segunda foi assinalada quando o campo estava incompleto, não preenchido ou ilegível, sendo identificada como item não preenchido.

Utilizou-se a análise descritiva por meio de distribuição de frequência e percentual de cada item no geral, estratificado por município. E, para a diferença entre os municípios, aplicou-se o teste Chi-Square para diferença de proporção. O programa fixou o $p$-valor em $0,5 \%$ para os testes e todas as análises foram realizadas no programa SAS for Windows versão 9.3 .

O estudo foi aprovado pelo Comitê de Ética em Pesquisa no 2.485.887 de 5 de fevereiro de 2018 , sendo seguido todas as recomendações contidas na Resolução $n^{\circ}$ 466 de 2012.

\section{Resultados}

Foi analisado um total de 159 Fichas de Investigação do Sistema de Informação de Agravos de Notificação da Coqueluche no período de janeiro de 2008 a dezembro de 2016 nos municípios de Botucatu e Marília. O referido total (159) representou $100 \%$ das fichas de investigação dos casos confirmados positivos para coqueluche de crianças entre zero e quatro 
anos de idade. Deste total, 72 (45,29\%) casos foram notificados no município de Botucatu e 87 (54,71\%) no município de Marília.

Os dados indicam que $100 \%(n=159)$ das fichas de notificação compulsória nos municípios de Botucatu e Marília, foram preenchidas parcialmente.

Quanto à apresentação dos resultados das fichas de notificação compulsória da doença coqueluche preenchidas parcialmente nos municípios estudados, optou-se por agrupá-los conforme a proposta de organização da própria ficha, dos quais serão apresentados descritivamente e como ilustração dos itens não preenchidos da ficha elaborou-se o Quadro 1, para melhor visualização crítica dos itens quanto a obrigatórios e facultativos.

Em se tratando dos itens referentes à categoria Dados Gerais, foi possível identificar que, sobre o item tipo de notificação, agravo da doença e data de notificação, os dados foram $100 \%$ preenchidos em ambos os municípios. $O$ campo referente ao Estado da notificação não foi preenchido em $2,78 \%$ das fichas de Botucatu e 1,15\% de Marília.

Quanto à Notificação Individual, o campo referente à idade do paciente notificado não foi preenchido em 2,78\% das fichas em Botucatu. Em relação ao sexo, no município de Marília, verificou-se que em $1,15 \%$ das fichas não foi preenchido. Quanto à informação sobre a gestação, raça e cor, esses dados não foram preenchidos por Marília em 2,30\%, já 0 item sobre a escolaridade correspondeu ao não preenchimento em $5,75 \%$. Em relação ao preenchimento do Cartão Nacional de Saúde (CNS), foi possível verificar em Botucatu que, de 72 fichas, $80,56 \% \quad(n=58)$ não foram preenchidas, ao passo que Marília, das 87 fichas, esta informação não foi preenchida em $49,43 \%(n=43)$.

\section{Os Dados de Residência mostram} que o Estado da residência do notificado não foi preenchido em $2,78 \%$ das fichas em Botucatu e 1,15\% em Marília, bem como o município de residência não foi informado por Marília em 3,45\% das fichas. Não apresentaram significância estatística. Quanto à identificação da localização do paciente investigado, os dados assinalam que o item de identificação do complemento da residência correspondeu a 97,22\% em Botucatu e 12,64\% de Marília de não preenchimento. Para o item de georreferenciamento (Geo) Campo 1 e 2, Botucatu apresentou $100 \%$ de não preenchimento e Marília 98,85\%.

$\mathrm{Na}$ categoria Antecedentes Epidemiológicos, a data da investigação foi preenchida em $100 \%$ das fichas de Botucatu e em 96,55\% de Marília. Referente à ocupação do notificado, este dado não foi preenchido em $77,78 \%$ das fichas por Botucatu e em 54,02\% por Marília. A resposta em relação à unidade notificante, se acaso era sentinela, ou seja, se o estabelecimento de saúde notificado é um serviço estratégico para maior 
controle epidemiológico da doença em estudo, não foi preenchida por Botucatu em $1,39 \%$ e por Marília em 9,20\% das fichas.

Em relação ao notificado ter tido contato com caso suspeito ou confirmado de coqueluche, este campo não foi preenchido por Botucatu em 1,39\% e por Marília em 5,75\% das fichas. No tocante ao nome do notificado, este não foi registrado por Botucatu em 94,44\% e por Marília em $72,41 \%$ das fichas.

O mesmo resultado se repetiu para Botucatu em relação ao preenchimento do endereço destes comunicantes e Marília não preencheu em $75,86 \%$ das fichas; o que dificulta a triagem para verificar a disseminação da doença, os valores dos dados apresentados desta categoria não tiveram diferença significativa.

Sobre o número de doses de vacina tríplice ou tetravalente que a criança notificada recebeu em Botucatu, não houve preenchimento deste item em $1,39 \%$, ao passo que em Marília 5,75\% das fichas deixaram de ser preenchidas, revelando que não houve significância entre os munícipios de $p=0,3301$. Quanto ao preenchimento da última dose das referidas vacinas, Botucatu não preencheu em 38,89\% e Marília em 34,48\% das fichas, não apresentando diferença significativa entre os municípios.

Quanto aos Dados Clínicos, verificou-se que a data do início da tosse e as complicações do paciente notificado não foram preenchidas por Marília em
$4,60 \%$, o mesmo se repetiu para os sinais e sintomas em $1,15 \%$.

Sobre o Atendimento, as informações referentes a hospitalizações, data da internação, município, Estado e nome da instituição, contidas nesta categoria foram preenchidas parcialmente pelos dois municípios, não apresentando significância estatística.

$\mathrm{Na}$ categoria Tratamento, os dados mostram que Marília não preencheu a informação do uso de antibiótico pelo notificante em $4,60 \%$ e a data de administração do mesmo não foi preenchida por Botucatu em 1,39\% e por Marília em $11,49 \%$ das fichas. Não apresentando significância estatística para os dois municípios.

Nos Dados Laboratoriais, a informação sobre a coleta de material da nasofaringe para cultura não foi preenchida por Marília em 4,60\%, entretanto a data da coleta do mesmo material não foi preenchida por Botucatu em $80,56 \%$ e por Marília em $6,90 \%$ das fichas. Os resultados destas culturas não foram preenchidos por Botucatu em $73,61 \%$ e por Marília em 43,68\%, nota-se que não houve diferença estatística.

Quanto às Medidas de Controle, os dados apresentados sobre a identificação dos comunicantes íntimos com o paciente investigado revelam o não preenchimento por Botucatu em 6,94\% e por Marília em $3,45 \%$ das fichas. Para a identificação da quantidade dos referidos comunicantes, não foi preenchido por Botucatu em 
$18,06 \%$ e por Marília em 14,94\% das fichas, não havendo significância deste último dado entre os dois municípios de $p=0,2791$. Com relação à informação de ter sido realizada a cultura nasofaringe entre os comunicantes, não houve preenchimento em 18,06\% para Botucatu e em $16,09 \%$ para Marília, não apresentando significância estatística em $p=0,1078$. Sobre a quantidade de comunicantes em que foi realizado este exame, Botucatu e Marília preencheram parcialmente estes itens $81,94 \%$ e $85,06 \%$ respectivamente, bem como em relação aos resultados dos mesmos com $12,50 \%$ em Botucatu e 27,59\% em Marília.

Para a realização de medidas de prevenção e controle, não foi realizado o preenchimento por Botucatu em 27,78\% e por Marília em 29,89\% das fichas, não apresentando significância estatística de $p=0,0851$.

$\mathrm{Na}$ Conclusão sobre a classificação final do paciente notificado, somente Marília não preencheu em $41,38 \%$ das fichas, o mesmo se repete para o critério de confirmação e descarte que deixou de ser preenchido por Marília em 22,99\%. Na informação sobre a doença estar relacionada ao trabalho, Botucatu e Marília preencheram parcialmente este item. Quanto à evolução da doença no paciente notificado, este dado não foi preenchido por Botucatu em 16,67\% e por Marília em $41,37 \%$. A informação sobre óbito, Botucatu não preencheu em 100\% das fichas e Marília em 95,40\%. No tocante à data de encerramento da investigação, Botucatu não preencheu 19,44\% ( $n=14)$ e Marília 45,98\% $(n=40)$ das fichas.

Quanto à categoria Investigador, os dados mostram que para a informação município da unidade de saúde, código da unidade notificante, nome e função do investigador, e campo assinatura, todos foram preenchidos parcialmente por ambos os municípios, não apresentando diferença estatística.

Quanto ao campo das informações adicionais, esperava-se encontrar observações sobre o resultado do PCR, o qual não foi preenchido por Botucatu em $87,50 \%$ e por Marília em 50,57\% das fichas, não apresentando significância estatística para ambos os municípios.

\section{Discussão}

O resultado de 159 fichas disponibilizadas para analise neste estudo, reforça a recomendação da literatura, que orienta que todos os casos suspeitos devem ser notificados e considerados positivos com base em critérios laboratoriais, como a cultura positiva e/ou RT-PCR; critérios epidemiológicos ${ }^{13}$.

Os resultados apontam 0 preenchimento parcial e corroboram com pesquisa realizada em 2005 no estado do Rio de Janeiro, a qual evidenciou que os dados disponibilizados pelo SINAN WEB não apresentavam todas as informações produzidas nas Fichas Individuais de Investigação, identificando erros de 
preenchimento, tanto na identificação correta dos acidentes, como no seu tratamento, as quais induzem erros nas políticas públicas e minimizam um problema real ${ }^{11}$.

Percebe-se que o tipo de notificação e agravo foi preenchido em $100 \%$ das fichas, talvez isso possa ocorrer pelo fato destes itens já estarem previamente preenchidos, o que seria relevante para minimizar os não preenchimentos. A mesma estratégia poderia ter sido realizada para o campo referente ao Estado da notificação, que não apresentou o mesmo preenchimento, tratando-se de uma ficha do estado de São Paulo, o referido item poderia vir preenchido, ainda por ser item considerado obrigatório na instrução para o preenchimento ${ }^{14}$.

Esta afirmação corrobora com estudos que reiteram a importância das informações adequadas que orientam estratégias no campo da saúde coletiva, seja ela local seja estadual ${ }^{11}$. Outros autores reforçam ao detectarem que não há uma compreensão dos serviços de saúde sobre a importância de dados estatísticos ${ }^{15}$.

Foi possível identificar, na categoria notificação individual, que a falta dos preenchimentos dos itens provoca impacto na vigilância epidemiológica da doença, o qual reforça a literatura, pois tais informações podem comprometer a eficácia das medidas de prevenção e controle disponíveis nos serviços de vigilância epidemiológica ${ }^{16,17}$. Cabe ressaltar, destes itens analisados, somente o campo escolaridade é considerado de preenchimento facultativo na ficha, portanto, o restante torna-se obrigatório ${ }^{14}$. Apesar de facultativo, o preenchimento sobre a escolaridade é uma informação relevante, sobretudo no que se refere a doenças transmissíveis, já que em muitos casos é necessário bloqueio na população de risco, pois esta prática visa obstruir imediatamente a disseminação da doença na população ${ }^{18}$.

Embora os achados da categoria dados de residência, não tenham significância estatística, são extremamente importantes para desenvolver políticas de controle e prevenção da doença, uma vez que determinam a população-alvo e, por se tratar de preenchimento obrigatório, não se fundamenta o não preenchimento ${ }^{14}$.

Um estudo ${ }^{19}$ realizado no interior do estado de São Paulo é corroborado com este achado, pois demonstrou que 0 georreferenciamento dos dados permitiu mostrar correlação entre os setores de ocorrência de infecção com a prevalência, podendo estabelecer, por intermédio dos mapas, regiões potenciais de maior risco de ocorrência da doença, tornando-se uma importante ferramenta de gestão em saúde. Sendo assim, a falta destas informações na ficha prejudica a avaliação epidemiológica da doença na região de acometimento, impactando nas ações de saúde.

A parcialidade de preenchimento na categoria antecedentes epidemiológicos 
colabora com a literatura que reforça a importância da vigilância em identificar os casos comunicantes para realização de bloqueio, evitando a disseminação da doença, garantindo a saúde pública por esta vigilância ${ }^{6,7}$.

Os resultados sobre 0 preenchimento do esquema vacinal revelam uma fragilidade das informações da criança em investigação, fato que interfere diretamente no controle epidemiológico adequado da doença. Portanto, reforçam estudos que destacam a vacinação como uma das melhores formas de reduzir substancialmente a prevalência de diferentes enfermidades potencialmente graves e, consequentemente, erradicá-las ${ }^{20}$.

Outro estudo transversal realizado na cidade de Cuiabá/MT demonstra, por meio da análise das cadernetas de vacinação, que apesar da situação vacinal estar em dia, ainda é preocupante o índice de atraso em relação às vacinas obrigatórias no primeiro ano de vida ${ }^{21}$, reforçando a necessidade do controle epidemiológico dessas informações.

O resultado de preenchimento parcial da categoria dados clínicos reforça as instruções para o preenchimento do Centro de Vigilância Epidemiológica (CVE) do estado de São Paulo ${ }^{14}$, pois este é um item obrigatório cuja informação colabora no controle e na disseminação da doença, portanto é indispensável seu preenchimento, porém a data do início da tosse é considerada pelas instruções como dado facultativo $^{14} \circ$ que sugere reavaliação, pois se trata de uma informação relevante para condução da investigação.

$\mathrm{Na}$ categoria atendimento, os resultados não apresentaram significância estatística e são considerados facultativos pela instrução de preenchimento oferecida $^{14}$, o que provoca uma reflexão em relação à necessidade destes itens estarem presentes na ficha.

Esses achados colaboram com o estudo que avaliou o preenchimento da ficha de notificação de violência doméstica e revelou que a extensão da ficha contribui para o surgimento de dificuldades dos profissionais e serviços de saúde em seu preenchimento ${ }^{15}$.

Quanto aos resultados da categoria tratamento, mesmo sem apresentarem significância estatística entre os municípios e também estarem inclusos como itens facultativos conforme as instruções do $\mathrm{CVE}^{14}$, o que reflete uma preocupação, uma vez que, por meio destas informações, é possível identificar se a condução de tratamento da doença está dentro da preconizada pelo CVE e Ministério da Saúde, pois a administração do antibiótico previamente à realização da cultura pode interferir no resultado. É possível evidenciar este fato nas orientações realizadas pela Secretaria de Vigilância em Saúde (SVS) no Ministério da Saúde, quando reforça que a coleta do espécime clínico deve ser realizada antes 
do início da antibioticoterapia e, no máximo, três dias após ${ }^{22}$.

Os resultados em relação aos dados laboratoriais, quanto ao seu preenchimento parcial, são preocupantes, pois além de constar nas instruções da ficha como item obrigatório ${ }^{14}$, está incoerente com o preconizado pela Divisão de Doenças de Transmissão Respiratória (DDTR) e com as orientações publicadas pela SVS, que preconiza o diagnóstico laboratorial considerado "padrão ouro" pelo alto grau de especificidade e nas ações de vigilância epidemiológica, ainda afirma que se deve assegurar 0 diagnóstico laboratorial ${ }^{13}$.

Os resultados em relação à medida de controle reforçam a finalidade da ficha de notificação compulsória sobre as doenças, que tem por objetivo a identificação (notificação) e a investigação das doenças, de modo rápido e eficaz dos $\operatorname{casos}^{16}$. Em consideração a este, não havendo preenchimento dos itens correspondentes aos comunicantes, ou mesmo a sua obrigatoriedade, cabe ressaltar como será possível tratar-se de uma ficha de investigação, se a mesma é realizada parcialmente conforme os achados deste estudo e os itens são facultativos conforme as próprias orientações para seu preenchimento ${ }^{14}$, dificultando a vigilância no controle e erradicação da doença.

A DDTR reforça, em suas orientações, que por se tratar de uma doença de transmissão direta, o comunicante pode ser considerado um disseminador da doença. Além disso, é preconizado para prevenir casos secundários evitar a disseminação da bactéria para a comunidade utilizando-se da quimioprofilaxia, tanto pela exposição ao paciente considerado positivo para coqueluche, quanto para evitar disseminação pelo portador da bactéria ${ }^{13}$.

Este relatório ${ }^{13}$ corrobora os achados desta pesquisa quando ressalta a importância das medidas de controle para os comunicantes utilizando-se da quimioprofilaxia.

Outras medidas também podem ser utilizadas para prevenção e controle, como a estratégia coccon - "casulo" em português - por meio da qual se protege o recém-nascido imunizando seus familiares e cuidadores, apresentando uma proteção ao redor da criança ${ }^{22}$. Outra pesquisa sugere uma dose de reforço na adolescência entre 11 e 17 anos como medida preventiva ${ }^{23}$.

No Brasil, atualmente, a medida de controle adotada foi a inclusão da vacina dTpa (Difteria, Tétano, Pertussis acelular) no calendário vacinal para gestantes e para profissionais da saúde que atuam em maternidades, berçários e Unidades de Terapia Intensiva (UTI) neonatais ${ }^{24}$.

Os resultados apresentados nas fichas sobre a conclusão da investigação, bem como as informações adicionais, das quais deveriam estar os resultados dos PCR, é relevante tratando de confirmação diagnóstica. Embora a instrução da 
Secretaria de Saúde do Estado, datada de 2006, considere que o preenchimento deste campo não seja obrigatório ${ }^{14}$, a literatura, em 2009, destaca a implementação - no estado de São Paulo, pelo Instituto Adolfo Lutz (IAL) - da adição de um método mais sensível de detecção da Bordetella pertussis, o RT-PCR, uma nova ferramenta diagnóstica adotada com o intuito de otimizar os resultados, sendo este um método mais rápido e de alta sensibilidade e especificidade paralelamente à cultura ${ }^{25}$.

Vale ressaltar que estas informações consideradas registros eletrônicos de saúde, são importantes para a gestão da saúde, pois, por intermédio destas, seria possível realizar intervenções de educação em saúde para os serviços e profissionais $^{11,15-17}$.

Resumidamente, este estudo constatou a falta de preenchimento de vários itens da ficha os quais são considerados facultativos na própria instrução do preenchimento, no entanto, são de extrema relevância para investigação e controle da doença. Com relação aos itens considerados obrigatórios, também preenchidos parcialmente, todos são relevantes para o controle epidemiológico. Estes achados promovem uma reflexão sobre o processo de trabalho que envolve as atividades de Vigilância Epidemiológica (VE) no cotidiano dos preenchimentos das fichas de investigação.
Diante desse contexto, um estudo que reforça essa discussão, objetivou focalizar a VE como uma forma de intervenção em Saúde Coletiva no modelo assistencial. Verificou-se que a enfermagem, considerada como um dos instrumentos a serviço das necessidades sociais de saúde dos grupos populacionais, integra a assistência voltada para a Vigilância à Saúde, na percepção da descentralização desta atividade. No entanto, as mesmas acumulam funções administrativas, resultando em pontos de vulnerabilidade na prática do trabalho em saúde, o qual deve ser reorientado para recompor o conjunto das práticas de forma articulada às demais práticas, integrando o processo de produção de serviços de saúde com os demais profissionais ${ }^{26}$. Assim ao pensar na adequação das fichas deve-se levar em conta o processo de trabalho da equipe de saúde com vista a subsidiar as boas práticas do trabalho.

\section{Conclusão}

Constatou-se, portanto, neste estudo, a necessidade imediata de ações de educação em saúde e comprometimento da gestão para que os serviços e profissionais de saúde recebam capacitação sobre a importância do preenchimento atento e integral de um instrumento de informação que determina ações epidemiológicas de controle e prevenção de doenças transmissíveis, 
bem como, a necessidade de revisão dos itens contidos na ficha, pela Secretaria de Saúde do Estado, em face das novas implementações na condução da investigação para a doença coqueluche e sua emergência, constituindo-se novas políticas de informação em saúde.

\section{Financiamento}

A autora principal recebeu incentivo com Bolsa CAPES de Demanda Social no período de março de 2016 a julho de 2017. Declara-se que este estudo é parte da tese de doutorado da autora principal Paula Fernandes Chadi, intitulada "Vacina dTpa em gestantes na redução da coqueluche na criança" ${ }^{27}$ defendida no ano de 2018 pela Universidade Estadual Paulista "Júlio Mesquita Filho".

\section{Agradecimentos}

Agradecemos às Secretarias de Saúde de Botucatu e de Marília e aos Serviços de Vigilância Epidemiológica dessas localidades pela colaboração no desenvolvimento da pesquisa, bem como ao Centro de Vigilância Epidemiológica (CVE) do estado de São Paulo por acreditar na importância da pesquisa.

Conflito de interesse: Os autores relatam que não há qualquer conflito de interesse na realização desta pesquisa.

\section{Referências}

1. Organización Mundial de la Salud. Reglamento Sanitario Internacional (1969). Tercera edición anotada. Ginebra; 1983.

2. World Health Organization. Revision of the International Health Regulations. Wkly Epidemiol Rec. 1996 Aug;71(31):233-5.

3. Brasil. Departamento de Imprensa Nacional. Portaria GM 1.100, de 24 de maio de 1996. Diário Oficial da União. Brasília; 1996, Seção I.

4. Brasil. Ministério da Saúde. Secretaria Nacional de Ações Básicas de Saúde. Divisão Nacional de Epidemiologia. Vigilância Epidemiológica e Imunizações Legislação Básica. $4^{\mathrm{a}}$ ed. Brasília:

Ministério da Saúde; 1978.

5. Brasil. Ministério do Estado da Saúde. Portaria n. 204, de 17 de fevereiro de 2016. Define a Lista Nacional de Notificação Compulsória de doenças, agravos e eventos de saúde pública nos serviços de saúde públicos e privados em todo o território nacional, nos termos do anexo, e dá outras providências. Brasília: Ministério da Saúde; 2016.

6. Brasil. Ministério da Saúde. Secretaria de Vigilância em Saúde. Departamento de Vigilância Epidemiológica. Sistema de Informação de Agravos de Notificação Sinan: normas e rotinas. $2^{\underline{a}}$ ed. Brasília: Editora do Ministério da Saúde; 2007. (Série A. Normas e Manuais Técnicos). 7. Brasil. Ministério da Saúde. Secretaria de Vigilância em Saúde. Departamento de Vigilância Epidemiológica. Guia de vigilância epidemiológica. $7^{\underline{a}}$ ed. Brasília: Ministério da Saúde; 2009. (Série A. Normas e Manuais Técnicos).

8. Da Silva GA, De Oliveira CMG. O registro das doenças de notificação compulsória: a participação dos profissionais da saúde e da comunidade. Rev Epidemiol Control Infect [Internet]. 2014 [citado 2017 jan. 17];4(3):215-20. 
Disponível em:

https://online.unisc.br/seer/index.php/epid emiologia/article/view/4578

9. Sousa MH de, Bento SF, Osis MJD, Ribeiro $\mathrm{M}$ de $\mathrm{P}$, Faúndes $\mathrm{A}$.

Preenchimento da notificação compulsória em serviços de saúde que atendem mulheres que sofrem violência sexual.

Rev. bras. epidemiol [Internet]. 2015 mar. [citado 2017 jan. 17];18(1): 94-107.

Disponível em:

http://www.scielo.br/scielo.php?script=sci arttext\&pid=S1415-

790X2015000100094\&lng=en

10. Laguardia J, Domingues CMA, Carvalho C, Lauerman CR, Macário E, Glatt R. Sistema de Informação de Agravos de Notificação (Sinan): desafios no desenvolvimento de um sistema de informação em saúde. Epidemiol. Serv. Saúde. 2004;13(3):135-47.

11. Bochner R, Guimarães CS, Santana RAL, Machado C. Qualidade da informação: a importância do dado primário, o princípio de tudo. In: Anais do $12^{\circ}$ Encontro Nacional de Pesquisa em Ciência da Informação; 2011. Brasília, DF: UNB; ANCIB; 2011. p. 3526-38.

12. Brasil. Ministério da Saúde. Guia de Vigilância Epidemiológica. $1^{\underline{a}} \mathrm{ed}$. Vol.1 Brasília; 2017.

13. Brasil. Secretaria de Estado da Saúde de São Paulo. Centro de Vigilância Epidemiológica "Prof. Alexandre Vranjac". Caderno de vigilância epidemiológica vigilância epidemiológica em saúde ambiental. São Paulo: Secretaria de Estado da Saúde; Centro de Vigilância Epidemiológica "Prof. Alexandre Vranjac" Divisão de Doenças Ocasionadas pelo Meio Ambiente; 2013.

14. São Paulo (Estado). Secretaria de Saúde do Governo do Estado de São Paulo. Centro de Vigilância

Epidemiológica. Coqueluche: Instruções para o preenchimento. Ficha de Investigação - Sinan NET. 2006. [Internet]. [citado 2017 ago. 2]. Disponível em:

http://portalsinan.saude.gov.br/images/doc umentos/Agravos/Coqueluche/Coqueluch e v5 instr.pdf

15. Sousa MH, Bento SF, Osis MJD, Ribeiro MP, Faúndes A. Preenchimento da notificação compulsória em serviços de saúde que atendem mulheres que sofrem violência sexual. Rev Bras Epidemiol. 2015;18(1):94-107.

16. Silva GA, Oliveira CMG. O registro das doenças de notificação compulsória: a participação dos profissionais da saúde e da comunidade. Rev Epidemiol Control Infect. 2014;4(3):215-20.

17. Cunha RE. Cartão Nacional de Saúde - os desafios da concepção e implantação de um sistema nacional de captura de informações de atendimento em saúde. Ciênc. Saúde Coletiva. 2002;7(4):869-78.

18. Souto BGA. Fundamentos epidemiológicos para a abordagem das doenças infecciosas. Rev Med Minas Gerais. 2009;19(4):364-71.

19. Neves VLFC, Katz G, Rodas LAC, Poletto DW, Lage LC, Spínola RMF, et al. Utilização de ferramentas de análise espacial na vigilância epidemiológica de leishmaniose visceral americana Araçatuba, São Paulo, Brasil, 1998-1999. Cad. Saúde Pública. 2001;17(5):1263-67. 20. De Sousa NLO, Noronha FMF, Machado MCAM, Diniz MRF, Nunes DS. Cobertura vacinal do esquema básico em menores de um ano em um centro de saúde do município de São Luís, MA. Rev. Investig. Bioméd. São Luís. 2014;6:71-81.

21. Abud SM, Gaíva MAM. Análise do preenchimento dos dados de imunização da caderneta de saúde da criança. Rev. Eletr. Enf. [Internet]. 2014 [citado 2017 ago. 19];16(1):61-7. Disponível em: http://dx.doi.org/10.5216/ree.v16i1.24254 22. Guiso N, Liese J, Plotkin S. The Global Pertussis Iniciative. Meeting report from the fourth Regional Roundtable 
Meeting, France, April 14-15, 2010. Hum Vaccin [Internet]. 2011 Apr [cited 2014 Oct 2]; 7(4): 481-8, 2011. Avaliable from: http://www.tandfonline.com/doi/pdf/10.416 1/hv.7.4.14528?needAccess=true 23. Zepp F, Heininger U, Mertsola J, Bernatowska E, Guiso N, Roord J, et al. Rationale for pertussis booster vaccination throughout life in Europe. Lancet Infect Dis. 2011;11: 557-70.

24. São Paulo (Estado). Secretaria de Estado da Saúde. Centro de Vigilância Epidemiológica "Professor Alexandre Vranjac". Divisão de Imunização. Informe Técnico - Vacina Difteria, Tétano e Coqueluche. São Paulo: CVE; 2014.

25. São Paulo (Estado). Secretaria de Estado da Saúde. Instituto Adolfo Lutz. Centro de Bacteriologia. Coqueluche: Manual de Diagnóstico Laboratorial. São Paulo; 2010.

26. Rodrigues VM, Fracolli LA, Oliveira MAC. Possibilidades e limites do trabalho de vigilância epidemiológica no nível local em direção à vigilância à saúde. Rev Esc Enferm USP 2001; 35(4): 313-9.

27. Chadi PF. Vacina dTpa em gestantes na redução da coqueluche na criança [tese]. Botucatu: Universidade Estadual Paulista "Júlio Mesquita Filho", Faculdade de Medicina de Botucatu; 2018. 


\section{Anexos}

Quadro 1: Demonstrativo dos itens da ficha de notificação compulsória para coqueluche em relação ao não preenchimento segundo os itens obrigatórios e facultativos nos municípios de Botucatu e Marília.

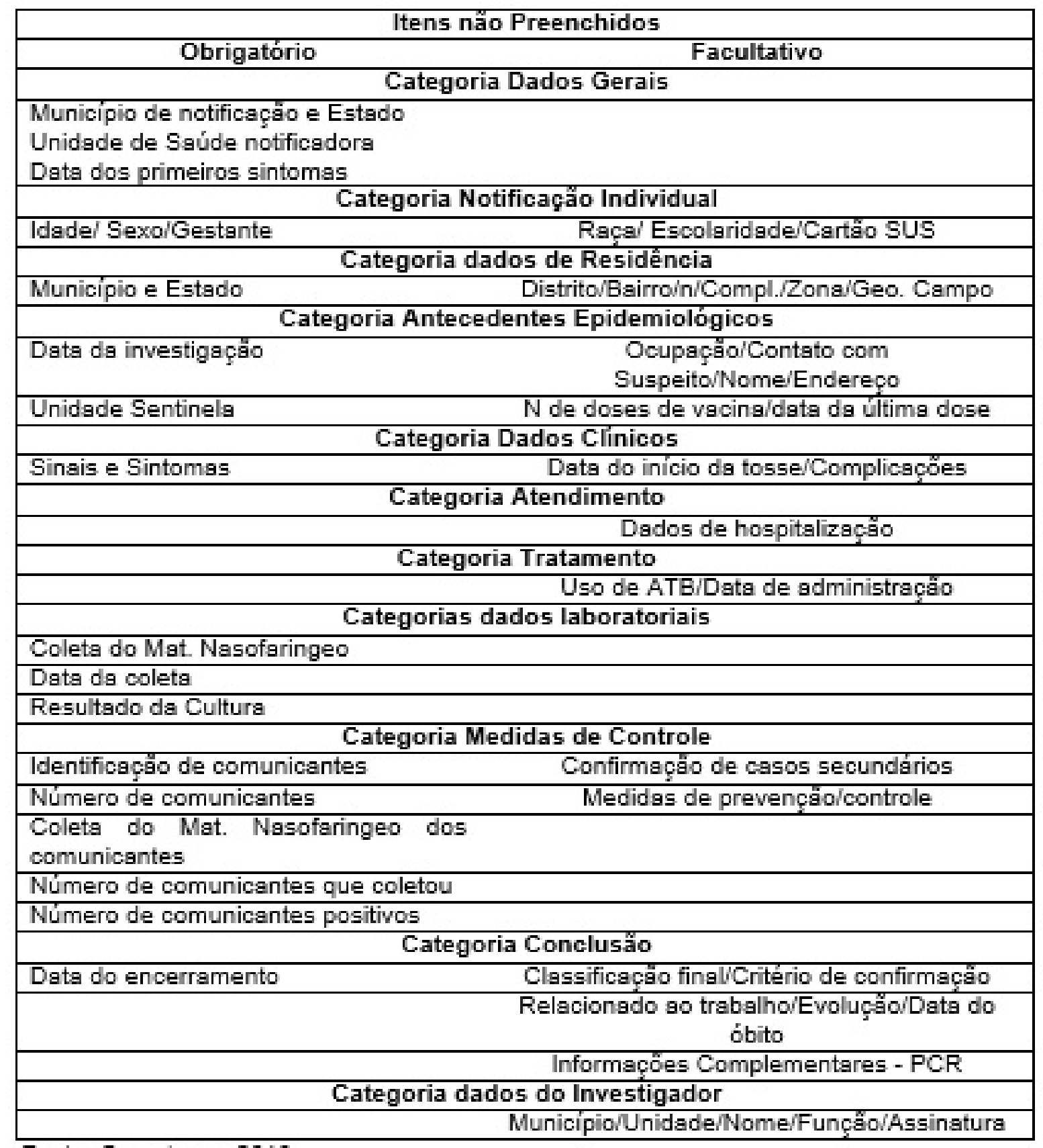

Fonte: Os autores, 2018.

RE. SAÚD. DIGI. TEC. EDU., Fortaleza, CE, v.4, n.2, p.20-34, ago./dez. 2019.

ISSN: 2525-9063 


\section{Como citar este artigo}

Chadi PF; Orso LF; Silva A de L; Oliveira RAP; Carvalho GC; Corrêa I. Avaliação da ficha de coqueluche dos casos positivos em dois municípios do interior paulista. Revista de Saúde Digital e Tecnologias Educacionais. [online], volume 4, n. 2. Editor responsável: Luiz Roberto de Oliveira. Fortaleza, mês e ano, p. 20-34. Disponível em: http://periodicos.ufc.br/resdite/index. Acesso em "dia/mês/ano".

Data de recebimento do artigo: 13/10/2019

Data de aprovação do artigo: 25/11/2019 